\title{
Anti-Corruption and Attraction Foreign Investment Case Study: Public Sector
}

\author{
Abdifatah Dahir Harun* \\ Somalia \\ *Corresponding Author: Abdifatah Dahir Harun, Somalia

\begin{abstract}
This study researcher focus on corruption and also FDI to contribute the of country development and prevent corruption any kinds of it. Also highlight these following: Table 4.2.18aboveandfigure 4.2.18belowindicate $44.4 \%$ of the respondents participated in this study strongly agreed and the $17.8 \%$ oftherespondentsparticipatedinthisstudy agreeand $17.8 \%$.

$\checkmark$ The findings of the study discovered that there is a weak relationship between the two variables indicating in Anti-corruption and attraction foreign investment

$\checkmark$ While their projects also rarely involve a transfer of investment to the local population, while their Turkish counterparts pay for seminars in Mogadishu developed investment program to help local business owners gain expertise. In an effort to address national investment concerns, Turkey has even begun strengthen its good relations with Somalia by using to train Somali expertise investment
\end{abstract}

\section{INTRODUCTION}

\subsection{Background of Study}

After the complete collapse of state institutions in 1991, Somalia represents one of the world's most protracted cases of statelessness (Bertelsmann Stiftung 2016). The on-going civil war, tensions between traditional clans and recurring famine ensure that the prospects for political stability remain bleak.

Corruption is both one of the leading causes and consequences of endemic political instability in Somalia, which has been ranked bottom of Transparency International's Corruption Perceptions Index every year since 2006. Corruption occurs at all levels in both the public and private sectors, and is a visible and expected form of behavior. It affects virtually every aspect of the Somali society: from public officials' misuse of public goods for private gain and the solicitation of bribes in exchange for basic services to the clan-based patronage networks used to obtain employment and political appointments. Businesses have likewise adjusted to the climate of lawlessness, for instance, by avoiding taxes and selling expired food and drugs (Marqaati 2017a; Legacy Centre for Peace and Transparency 2016).

Despite a comparatively peaceful transition of power to a newly elected president in early 2017 , there are as yet few signs of comprehensive anti-corruption reform. The country's institutions continue to be extremely dysfunctional, and there are limited integrity mechanisms in place to curb corruption; among other things, the National Anti-Corruption Commission foreseen in the constitution has yet to be established (GAN Integrity 2016; Marqaati 2017a).

Foreign direct investment is a phenomenonresulting from globalization, which involvesthe integrationof the domestic economic system with global markets. It is accomplishedthrough opening up of the local economic sector as well as domestic capital for foreign investors to establishbusiness, within the economy. When thereis a rise in capital movement within several countries, it results in financial globalization. Domestic lenders and borrowers take part in the international market with the use of global financial intermediaries(Macionis\& Plummer, 2005). Financial globalization in developing countries is mainly favored by the availability of cheap labor and the fact that, return on capital is relatively high (Obstfeld \&Rogoff, 1996). In the recent years, there has been a rise in the amount of capital that has been flowing in to developing countries. Foreign companies investing in developing countries are significant in facilitating economic growth (Feenstra, 2003). 


\section{LITERATURE REVIEW}

\subsection{The Role of Anti- Corruption}

Corruption was deemed a widespread problem during the brief tenure of Somalia's coalition government. The unity administration was formed in 2008 after a UN-brokered conference in Djibouti between representatives of the Somali Transitional Federal Government (TFG) and the moderate Islamist Alliance for the Re-liberation of Somalia (ARS), which ended in an agreement calling for the expansion of parliament to 550 seats in order to accommodate the new ARS members.

Shortly afterwards, Transparency International ranked Somalia in last place on its annual Corruption Perceptions Index (CPI), a metric that purports to show the prevalence of corruption in a country's public sector. A 2012 World Bank report also alleged that about $\$ 130$ million or $68 \%$ of funds that the coalition government had received over this 2009 and 2010 period was unaccounted for.

An earlier 2011 paper prepared for the TFG by the Public Finance Management Unit, a Somali government body tasked with overseeing the nation's fiscal management, similarly suggested that over $\$ 70$ million in cash payments from Arab donor countries were missing over the same 2009-2010 period. Largely based on interviews with Mogadishu politicians who had witnessed the payments or received funds, the report alleged that a total of $\$ 300$ million were unaccounted for once internal revenue was also taken into consideration. By contrast, funds from Western nations nominally earmarked for security and social service-related initiatives in Somalia mainly went directly to aid agencies, with very little of it ultimately reaching the Somali authorities. According to then Finance Minister Hussein Halane, although government officials routinely deposited foreign contributions in the Central Bank of Somalia, some of the money was first spent on legitimate and documented expenses.

In July 2012, a report by the UN Monitoring Group on Somalia and Eritrea (SEMG) submitted to the UN Security Council again alleged that between 2009 and 2010, around 70 percent of funds that had been earmarked for development and reconstruction in Somalia were unaccounted for. President Sharif Sheikh Ahmed rebuked the claims, indicating in particular that a \$3 million payment from the Government of Oman had gone toward legitimate government expenses, including loans, security forces and parliament. Ahmed also asserted that the SEMG paper had been "timed to coincide with the end of [the] transition period in order to discredit the TFG," and that the Monitoring Group was the "wrong approach for Somalia's peace and development. Additionally, the Prime Minister's Office released a statement describing the report as misleading and false, and suggested that it would consider filing a defamation and libel lawsuit if some of the accusations contained in the paper were not retracted.

\subsection{Anti-Corruption Measures}

In 2010, a new technocratic administration was appointed to office, which enacted a number of reforms, including measures to tackle purported graft within the public sector. According to the Prime Minister, Cabinet ministers fully disclosed their assets and signed a code of ethics in order to improve transparency. An Anti-Corruption Commission with the power to carry out formal investigations and to review government decisions and protocols was also established so as to more closely monitor all activities by public officials. Furthermore, unnecessary trips abroad by members of government were prohibited, and all travel by ministers subsequently required the Prime Minister's consent.

A budget outlining 2011's federal expenditures was also put before and approved by members of parliament, with the payment of civil service employees prioritized. In addition, a full audit of government property and vehicles was put into place.

Following the London Somalia Conference held in February 2012, Somali and international stakeholders further upheld existing plans to establish a joint financial management board in order to ensure a transparent dispensation of Somali and donor funds. They also pledged support for Somalia's stable regions, agreeing to form a new fund earmarked for local dispute resolution, job creation, basic service delivery and development of government sectors. In addition, the U.S. government indicated that it would lobby for the imposition of sanctions on all parties impeding political progress made by the Somali Transitional Federal Government, including pre-emptive measures such as travel bans and asset freeze. 


\subsection{Role FDI in Somalia}

According to GraziaIetto-Gillies (2012), prior to Stephen Hymer's theory regarding direct investment in the 1960s, the reasons behind foreign direct investment and multinational corporations were explained by neoclassical economics based on macro-economic principles. These theories were based on the classical theory of trade in which the motive behind trade was a result of the difference in the costs of production of goods between two countries, focusing on the low cost of production as a motive for a firm's foreign activity. For example, Joe S. Bain only explained the internationalization challenge through three main principles: absolute cost advantages, product differentiation advantages and economies of scale. Furthermore, the neoclassical theories were created under the assumption of the existence of perfect competition. Intrigued by the motivations behind large foreign investments made by corporations from the United States of America, Hymer developed a framework that went beyond the existing theories, explaining why this phenomenon occurred, since he considered that the previously mentioned theories could not explain foreign investment and its motivations.

Facing the challenges of his predecessors, Hymer focused his theory on filling the gaps regarding international investment. The theory proposed by the author approaches international investment from a different and more firm-specific point of view. As opposed to traditional macroeconomics-based theories of investment, Hymer states that there is a difference between mere capital investment, otherwise known as portfolio investment, and direct investment. The difference between the two, which will become the cornerstone of his whole theoretical framework, is the issue of control, meaning that with direct investment firms are able to obtain a greater level of control than with portfolio investment. Furthermore, Hymer proceeds to criticize the neoclassical theories, stating that the theory of capital movements cannot explain international production. Moreover, he clarifies that FDI is not necessarily a movement of funds from a home country to a host country, and that it is concentrated on particular industries within many countries. In contrast, if interest rates were the main motive for international investment, FDI would include many industries within fewer countries.

Another observation made by Hymer went against what was maintained by the neoclassical theories: foreign direct investment is not limited to investment of excess profits abroad. In fact, foreign direct investment can be financed through loans obtained in the host country, payments in exchange for equity (patents, technology, machinery etc.), and other methods. The main determinants of FDI is side as well as growth prospectus of the economy of the country when FDI is made. Hymer proposed some more determinants of FDI due to criticisms, along with assuming market and imperfections. These are as follows:

1. Firm-specific advantages: Once domestic investment was exhausted, a firm could exploit its advantages linked to market imperfections, which could provide the firm with market power and competitive advantage. Further studies attempted to explain how firms could monetize these advantages in the form of licenses.

2. Removal of conflicts: conflict arises if a firm is already operating in foreign market or looking to expand its operations within the same market. He proposes that the solution for this hurdle arose in the form of collusion, sharing the market with rivals or attempting to acquire a direct control of production. However, it must be taken into account that a reduction in conflict through acquisition of control of operations will increase the market imperfections.

3. Propensity to formulate an internationalization strategy to mitigate risk: According to his position, firms are characterized with 3 levels of decision making: the day to day supervision, management decision coordination and long term strategy planning and decision making. The extent to which a company can mitigate risk depends on how well a firm can formulate an internationalization strategy taking these levels of decision into account.

Hymer's importance in the field of International Business and foreign direct investment stems from him being the first to theorize about the existence of multinational enterprises (MNE) and the reasons behind FDI beyond macroeconomic principles, his influence on later scholars and theories in international business, such as the OLI (Ownership, Location and Internationalization) theory by John Dunning and Christos Pitelis which focuses more on transaction costs. Moreover, "the efficiencyvalue creation component of FDI and MNE activity was further strengthened by two other major scholarly developments in the 1990s: the resource-based (RBV) and evolutionary theories" ${ }^{\text {[5] }}$ In addition, some of his predictions later materialized, for example the power of supranational bodies such as IMF or the World Bank that increases inequalities (Dunning \&Piletis, 2008) 


\section{Methodology}

In this chapter, the research methodology was discussed research design, research population, sample size, sampling procedure, research instrument, date gathering procedure, reliability and validity of the in instrument, date analysis, ethical consideration and limitations.

\subsection{Research Design Study}

Were accomplish thought a correlation study; the purpose of the correlation research is to describe an accurate report of the relationship between two variables. Correlation is a research design where the researchers may determine of whether or not relationship exists between two or more variables collects data from two variables for the same group of subjects. The researchers" purpose is to explore the relationship between two characteristics from the same group and explain how characteristics vary together. Correlation design is ideally suitable for studies where independent variable have relationship with dependent variable (One, 2008).

\subsection{Target Population}

This study were be conducted among the two public sector institutions in Mogadishu.

\subsection{Sample Size}

The institution in Somalia were be the target population of the study and all of them were study as the number were small. One of the top management staff were fill up the questionnaire.

\subsection{Sampling Procedures}

The sampling procedures of this study were used probability sampling procedures particularly purposive or judgmental sampling. The researcher wereselect this sampling technique because it gives the opportunity to select the member target population who provides the accurate information or date. Judgmental sampling is a way of sampling where the research uses his/her judgment to choose population number who is good prospects for precise information or date (Saunders et al, 2009).

\subsubsection{Validity Analysis}

The measure is considered valid when it actually measures what it is intended to measure (Churchill, 1979). Validity ensures the ability of a scale to measure the intended concept. Literature suggests research of this type to have three groups of validity: content validity, criterion validity and construct validity (Sekaran, 2003). To make sure the validity and reliability of the questionnaire used for the study, researcher were use SPSS to look at the questionnaire items in relation to its ability to achieve the stated objectives of the research, level of coverage, comprehensibility, logicality and suitability for prospective respondents.

\subsubsection{Reliability Analysis}

Reliability test were conduct on scale measures using Cranach"s Alpha. Cronbach"s Alpha Test were employ to determine variable reliability. Cranach"s Alpha values of more than 0.6 Indicate high reliability. This is the most commonly used test for scale reliability. Reliability is the capacity of a measure to produce consistent results? The value of the Alpha coefficient Ranges between 0 and 1 . The more the value closes to 1 , the high the level of consistency among the items. The reliability of a measure indicates the extent to which it is without bias and ensures consistent measurement across time and various items. It is a measure of stability and consistency with which instrument measures the concept (Sekaran, 2003). The inter-item consistency reliability were test - 26 - using a popular method suggested by Cronbach. He proposed coefficient Alpha called (Cronbach Alpha) for multipoint scaled items. The higher the coefficients, the better the measuring instrument (Sekaran, 2003)

\subsection{Research Instrument}

Primary data were collect employing questionnaire with close-ended questions. The questionnaire were design in such a way that enables to collect the relevant data. The operators "e questionnaire consists of two sections: the first section is demographic data; the second is about the operations of the institutions. The clients "e questionnaire consists of the same two sections but different question.

\subsection{Data Analysis}

Statistical package for social science (SPSS) version 20 would be used to analyze the data collection of this study, because it is not easy to analyze the data collected in a study manually without using any statistical packages. 
Mean Range Scale Interpretation

4.21-5.00 strongly agree Very High

3.41-4.20 Agree High

2.61-3.40 Neutral Normal

1.81-2.60 Disagree Low

$27-1.00-1.80 \quad$ strongly disagree Very low

\subsection{Ethical Considerations}

Generally, job creation did not like to answer questions that tried to probe into their incomes, earnings from their services, family life and expenditure. Researcher was tryduring interactions with them to avoid asking respondents such questions and researchers were consider ethical issue during research project, and this can be accomplished by exercising privacy, confidentiality and anonymity

\subsection{Limitations of the Study}

The major limitation of this study are; first, the census of the population was difficult to get as well as the sample was estimated by researchers by adopting foreign studies; second, the language is also the greatest barrier in getting the most correct answers for the questionnaire; next, the survey instrument used in this study was only questionnaire, since there are other suitable methods like questionnaire with interview; finally, extraneous variables was outside the researchers control including honesty, personal biases .

\section{DATA PRESENTATION, ANALYSIS AND DISCUSSION OF FINDINGS}

\subsection{Introduction}

In this chapter will be presented and discussed the data had been analyzed by using SPSS software; it will used in both tabular from containing the type of responses, its frequencies, percentages, valid percentages and cumulative percentages.

\subsection{Demographic Data}

Table4.1.1. Shows Gender of the respondents

\begin{tabular}{|l|l|l|l|l|l|}
\hline \multicolumn{2}{|c|}{} & Frequency & Percent & Valid Percent & Cumulative Percent \\
\hline \multirow{3}{*}{ Valid } & Male & 20 & 45.5 & 45.5 & 45.5 \\
\cline { 2 - 7 } & Female & 24 & 54.5 & 54.5 & 100.0 \\
\cline { 2 - 7 } & Total & 44 & 100.0 & 100.0 & \\
\hline
\end{tabular}

Table4.1aboveandfigure4.1belowIllustratethegenderofrespondents, a total of $\mathbf{5 4 . 5 \%}$ of respondents participated in this studyweremaleemployeesand45.5\% were female employees there were total of 44respondents.

Table4.2. Shows Foreign direct investment is one of the imperative movement and it came in host country the form of physical mass like building, profound machineries.

\begin{tabular}{|l|l|l|l|l|l|}
\hline \multicolumn{2}{|c|}{} & Frequency & Percent & Valid Percent & Cumulative Percent \\
\hline \multirow{5}{*}{ Valid } & strongly disagree & 10 & 22.2 & 22.7 & 22.7 \\
\cline { 2 - 7 } & Disagree & 12 & 26.7 & 27.3 & 50.0 \\
\cline { 2 - 7 } & Agree & 14 & 31.1 & 31.8 & 81.8 \\
\cline { 2 - 7 } & strongly agree & 8 & 17.8 & 18.2 & 100.0 \\
\cline { 2 - 6 } & Total & 44 & 97.8 & 100.0 & \\
\hline
\end{tabular}

Table 4.2.2aboveandfigure 4.2.2belowindicate $31.1 \%$ of the respondents participated in this study strongly agreed and the $26.7 \%$ of the respondents participated in this study agreeand $22.2 \%$.

Table4.3. Shows the Role of Anti- Corruption

\begin{tabular}{|l|l|l|l|l|l|}
\hline \multicolumn{2}{|c|}{} & Frequency & Percent & Valid Percent & Cumulative Percent \\
\hline \multirow{4}{*}{ Valid } & strongly disagree & 11 & 24.4 & 25.0 & 25.0 \\
\cline { 2 - 7 } & Disagree & 13 & 28.9 & 29.5 & 54.5 \\
\cline { 2 - 7 } & Agree & 5 & 11.1 & 11.4 & 65.9 \\
\cline { 2 - 7 } & strongly agree & 15 & 33.3 & 34.1 & 100.0 \\
\hline
\end{tabular}




\begin{tabular}{|l|l|l|l|l|l|}
\hline \multicolumn{5}{|c|}{} \\
\hline & Total & 44 & 97.8 & 100.0 & \\
\hline
\end{tabular}

Table 4.2.15aboveandfigure 4.2 .15 belowindicate $24.4 \%$ of the respondents participated in this study strongly agreed and the $28.9 \%$ of the respondents participated in this study agree and $33.3 \%$ of the respondents participated in this study responded neutral and lastly, the remainingof $11.1 \%$ respondents disagreed.

\subsection{Chapter Summary}

Table 4.2.18aboveandfigure 4.2.18belowindicate $44.4 \%$ of the respondents participated in this study strongly agreed and the $17.8 \%$ of the respondents participated in this study agree and $17.8 \%$ of the respondents participated in this study responded neutral and lastly, the remaining of $17.8 \%$ respondents disagreed. Table 4.2.19 above and figure 4.2.19belowindicate $37.8 \%$ of the respondents participated in this study strongly agreed and the $20.0 \%$ of the respondents participated in this study agreeand $28.9 \%$ oftherespondents participated in this study responded neutral and lastly, the remaining of $11.1 \%$ respondents disagreed.

Table 4.2.20aboveandfigure 4.2.20belowindicate $40.0 \%$ of the respondents participated in this study strongly agreed and the $31.1 \%$ of the respondents participated in this study agree and $17.8 \%$ of the respondents participated in this study responded neutral and lastly, the remaining of $8.9 \%$ respondents disagreed.

Table 4.2.10 above and figure 4.2.10 below indicate $31.1 \%$ of the respondents participated in this study strongly agreed and the $48.9 \%$ of the respondents participated in this study agreeand $17.8 \%$ of the respondents participated in this study responded neutral and lastly, the remaining of respondents disagreed.

\section{CONCLUSION AND RECOMMENDATION}

\subsection{Conclusion}

$>$ The findings of the study discovered that there is a weak relationship between the two variables indicating in Anti-corruption and attraction foreign investment

$>$. This means that when the external actors rises then affect internal. In this part of the research is discussing results and findings derived from structured questionnaire of the relationship betweenAnti-corruption and attraction foreign investmentin Mogadishu Somalia.

$>$ To identify the corruption and attraction foreign investmentin in Mogadishu Somalia. According to the respondents were asked 6 questions about the objective one of the study which is the strategies used by

To identify the interest of external anti-corruption on external actors in Mogadishu-Somalia, the mean index is 4.2 which indicates agree level 6.2

\subsection{Recommendation}

$>$ Consult Somali Diaspora to make a major contribution to the Somali economy and livelihoods through investment

$>$ These two opportunities are most important economic sectors that can be invested by Somali Diaspora and local community to develop their business

$>$ Turkish investment differ others are in their expected returns; development countries sign contracts trading infrastructure projects for rights to natural resources.

$>$ While their projects also rarely involve a transfer of investment to the local population, while their Turkish counterparts pay for seminars in Mogadishu developed investment program to help local business owners gain expertise. In an effort to address national investment concerns, Turkey has even begun strengthen its good relations with Somalia by using to train Somali expertise investment.

\section{REFERENCES}

[1] National Anti-Corruption Commission foreseen in the constitution has yet to be established (GAN Integrity 2016; Marqaati 2017a). 
[2] Global financial intermediaries (Macionis \& Plummer, 2005).

[3] return on capital is relatively high (Obstfeld \& Rogoff, 1996

[4] protracted cases of statelessness (Bertelsmann Stiftung 2016).

[5] Foreign companies investing in developing countries are significant in facilitating economic growth (Feenstra, 2003).

[6] According to Grazia Ietto-Gillies (2012), prior to Stephen Hymer's theory regarding direct investment in the $1960 \mathrm{~s}$

[7] IMF or the World Bank that increases inequalities (Dunning \& Piletis, 2008)

\section{AUTHORS' BIOGRAPHY}

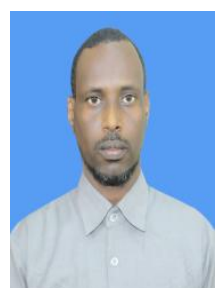

AbdifatahDahirHarun, have (MFM)-Master Financial Management at Amity University Uttar Pradesh, India, and B.SC. Public Administrationat HorseedInternational University Mogadishu, Somalia. More than 8 years' experience of Government Administration as programme coordination of Galmudug State and lecturing at Horseed International University. Also, I amthe founder of Haldoor Institute which offers professional subjects and vocational training courses.

I have publications more three articles some of them published here and other journals

Citation: Abdifatah Dahir Harun. "Anti-Corruption and Attraction Foreign Investment Case Study: Public Sector" International Journal of Humanities Social Sciences and Education (IJHSSE), vol 7, no. 6, 2020, pp. 168-174. doi: http://dx.doi.org/10.20431/2349-0381.0706018.

Copyright: (C) 2020 Authors. This is an open-access article distributed under the terms of the Creative Commons Attribution License, which permits unrestricted use, distribution, and reproduction in any medium, provided the original author and source are credited. 